\title{
Foreign bodies in digestive tract of children: A tertiary care hospital experience
}

\section{Ram Badan Singh, Rajeev Kumar Dubey, Vaibhav Pandey ${ }^{1}$, Vijayendra Kumar', Shiv Prasad Sharma ${ }^{1}$, Baghel Annavi ${ }^{2}$}

Departments of Anaesthesiology and ${ }^{1}$ Paediatric Surgery, Institute

of Medical Sciences, Banaras

Hindu University, Varanasi, ${ }^{2}$ SSPG Hospital, Kabir Chaura, Varanasi, India

Address for the Correspondence:

Dr. Ram Badan Singh, Department of Anaesthesiology, Institute of Medical Sciences,

Banaras Hindu University, Varanasi - 221005 ,

Uttar Pradesh, India.

E-mail: rambadan.vns@gmail.com

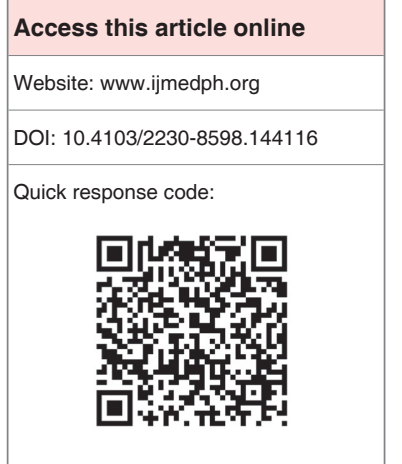

Introduction: Foreign bodies in the digestive tract are an important cause of morbidity and mortality in paediatric age group and pose diagnostic and therapeutic challenges We performed this study to evaluate our experience of foreign bodies of digestive tract in children over a five year period in a tertiary referral center. Patients and Method: $A$ retrospective study was conducted over a 5-year period between April 2009 and March 2013. All patients who were managed for foreign body in digestive tract up to 12 years of age were included and analysis was performed from case record of patients. Results: Total 97 patients with FB in digestive tract were included in the study FB was most commonly lodged in Upper esophagus in 61 patients, middle esophagus in 12 cases lower third of esophagus in 14 cases and beyond gastro-oesophageal junction in 10 cases. The most common clinical presentations were dull pain. Coins were the most common type of foreign body in the esophagus accounting for $71.1 \%$ of patients. Plain neck and chest $\mathrm{x}$-rays antero-posterior and lateral view was diagnostic in all cases, with all FB being opaque. Rigid oesophagoscopy and removal under general anesthesia was the main treatment modality performed in $63(65.8 \%)$ and Magill forceps extraction was done in 20 cases. Conclusion: Foreign bodies in digestive tract of children are a common problem with diverse presentation. Disc battery ingestion is prone for complication and expedient removal is required \& associated conditions can pose risk for lodgment of foreign bodies.

Key words: Anesthesia, digestive tract, foreign body

\section{INTRODUCTION}

Foreign bodies (FBs) in the digestive tract are an important cause of morbidity and mortality in pediatric age group, and pose diagnostic and therapeutic challenges. ${ }^{[1,2]}$ Most commonly, children in their first 6 years of life are affected, with a peak incidence in children between 1 and 3 years. ${ }^{[2,3]}$ The clinical presentation depends on site, nature, age of patient, and duration. ${ }^{[4]}$ Spectrum of clinical manifestations ranges from asymptomatic to long-term complication like esophageal stricture. We performed this study to present our experience of foreign bodies of digestive tract in children over a 5-year period. ${ }^{[5,6]}$

\section{PATIENTS AND METHODS}

A retrospective study was conducted in the Department of Pediatric Surgery, S.S. Hospital, Banaras Hindu University, Varanasi, over a 4-year period between April 2009 and March 2013. All patients who were managed for FB in digestive tract up to 12 years of age presenting during the study period were included. Data were collected, using case records of patient, regarding age, gender, duration, type, anatomical location of $\mathrm{FB}$, treatment given, duration of hospital stay, intervention performed for removal, anesthesia technique, complications, and mortality. All patients were anesthetized with injection pentazocin lactate $0.5 \mathrm{mg} / \mathrm{kg}$, thiopentone $5 \mathrm{mg} / \mathrm{kg}$, and suxamethonium $1.5 \mathrm{mg} / \mathrm{kg}$ body weight, followed by intermittent positive pressure ventilation. After laryngoscopy and visualization of FB in esophagus, Magill forceps was applied to hold and remove FB. Patients were ventilated with a bag and mask up to full recovery of spontaneous respiration. In those patients where FB was not visible during laryngoscopy, airway secured with endotracheal tube and anesthesia was maintained with oxygen, nitrous oxide, halothane and atracurium. Rigid esophagoscope was passed in esophagus and FB was removed. FB located below the esophagus was removed by operative intervention. All patients were reversed from anesthesia using injection glycopyrrolate $10 \mu \mathrm{g} / \mathrm{kg}$ and neostigmine $50 \mu \mathrm{g} / \mathrm{kg}$ body weight, and shifted in ward for observation. 


\section{RESULTS}

A total of 97 patients with FB in the digestive tract were included in the study. FB was most commonly logged in upper esophagus in 61 patients, middle esophagus in 12 cases, lower third of esophagus in 14 cases, and beyond gastro-esophageal junction in 10 cases. Sixteen $(16.4 \%)$ patients presented to the hospital within $24 \mathrm{~h}$, whereas $71(73.1 \%)$ presented between 1 day and 5 days, and the remaining $10(10.3 \%)$ presented to the hospital after 5 days [Table 1]. A positive history of FB ingestion was recorded in $76(78.3 \%)$ of cases, whereas in the remaining $21(21.6 \%)$ patients the diagnosis of FB in the digestive tract was made based on clinical presentation and radiological investigation on admission. Ninety (92.7\%) patients were asymptomatic at admission.

The most common clinical presentations were dull pain, odynophagia, vomiting, drooling of saliva, and difficulty in swallowing coins were the most common type of $\mathrm{FB}$ in the esophagus accounting for $71.1 \%$ of patients [Table 2, Figure 1]. Plain neck and chest X-rays anteroposterior and lateral view was diagnostic in all cases, with all FB being opaque. The patients with FB in upper esophagus were anesthetized with injection pentazocin lactate $0.5 \mathrm{mg} / \mathrm{kg}$, thiopentone $5 \mathrm{mg} / \mathrm{kg}$, and suxamethonium $1.5 \mathrm{mg} / \mathrm{kg}$ body weight, followed by intermittent positive pressure ventilation. After laryngoscopy and visualization of FB in esophagus, Magill forceps was applied to hold and remove FB. All patients were ventilated with a bag and mask up to full recovery of spontaneous respiration. In those patients where $\mathrm{FB}$ was not visible during laryngoscopy were intubated and anesthesia was maintained with oxygen, nitrous oxide halothane and atracurium. Rigid esophagoscope was passed in esophagus to remove FB. Patients were reversed from anesthesia and shifted in ward for observation. Magill forceps extraction was the main treatment modality performed in 63 (65.8\%); and rigid esophagoscopy and removal under general anesthesia was done in 20 cases out of 87 cases having FB above gastro-esophageal junction. In remaining four cases, sharp FB was pushed in stomach and was retrieved by laparotomy in same sitting [Figure 2]. In 10 (10.3\%) patients with FB below gastro-esophageal junction, two patients

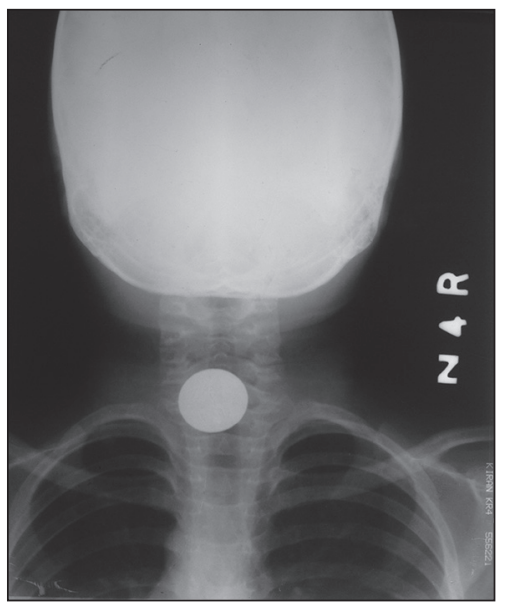

Figure 1: Coin in esophagus with sharp open safety pins, one case needle, and one case with button battery and peritonitis required laparotomy. In five cases FB passed spontaneously. In one follow-up case of common cloaca with colostomy and stenosis, FB removal was performed under general anesthesia. Two follow-up cases of tracheo-esophageal fistula (TEF) presented with lodged peanut at anastomotic site. In two cases with battery ingestion, acquired TEF repair was performed after 6 weeks of gastrostomy performed during first hospital stay [Figure 3]. A total of $68(82.9 \%)$ required at least an overnight hospitalization to be able to monitor immediate postoperative complications resulting from

\begin{tabular}{lcc}
\hline Table 1: Patient's characteristics & \\
\hline Characteristic & Number of patients & Percentage \\
\hline Age & 61 & 62.9 \\
0-5 years & 28 & 28.9 \\
5-10 years & 8 & 8.2 \\
10-15 years & 97 & 100 \\
Total & & \\
Gender & 55 & 56.7 \\
Male & 42 & 43.3 \\
Female & 97 & 100 \\
Total & & \\
\hline
\end{tabular}

\begin{tabular}{|c|c|c|}
\hline Type of FB & Number & Percentage \\
\hline Coins & 69 & 71.1 \\
\hline Buttons & 6 & 6.1 \\
\hline Batteries & 4 & 4.1 \\
\hline Needles & 4 & 4.1 \\
\hline Screws & 4 & 4.1 \\
\hline Safety pin & 3 & 3.0 \\
\hline Hair pin & 2 & 2.0 \\
\hline Locket & 2 & 2.0 \\
\hline Nose ring & 1 & 1.0 \\
\hline Metal plate & 1 & 1.0 \\
\hline Locket & 1 & 1.0 \\
\hline Total & 97 & 100 \\
\hline
\end{tabular}

$\mathrm{FB}=$ Foreign bodies

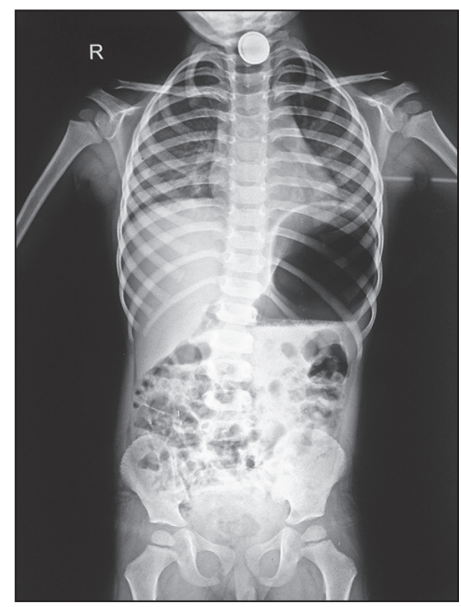

Figure 2: Button battery ingestion leading to tracheo-esophageal fistula 
the procedure and anesthesia. Twelve postoperative complications were recorded [Table 3].

\section{DISCUSSION}

Foreign body inhalation is common worldwide. ${ }^{[1]}$ Children aged between 1 and 5 years of age are commonly affected. ${ }^{[2,3]}$ In this study, the majority of patients were children aged 5 years and below, which is in agreement with other studies. ${ }^{[2,3]}$ Overactive nature of male children as compared with the females may be attributed to male preponderance in our study $(\mathrm{M}: \mathrm{F}=1.4: 1)$, which is in agreement with other studies. ${ }^{[6,7]}$ Fifty-nine $(71.9 \%)$ of the patients were asymptomatic on admission. In this study, a positive history of $\mathrm{FB}$ in the aerodigestive tract was recorded in $93.9 \%$ of cases and $69.4 \%$ of these were found to be asymptomatic on admission which is comparable to other studies. ${ }^{[8]}$ Esophagus is the most common site of FB impaction, followed by laryngo-tracheobronchial tree. ${ }^{[9]}$ Once FB crosses the cricopharynx, it can pass whole gastrointestinal tract. The majority of swallowed foreign bodies pass harmlessly and spontaneously through the gastrointestinal tract, ${ }^{[10]}$ but in case of lodgment or toxicity of the object, the FBs must be rapidly identified and removed. Most frequent lodgment site in our study was at cricopharyngeal muscle, which is in agreement with the literature. ${ }^{[11,12]}$ Sharp items can lodge anywhere, and patients who have esophageal abnormalities such as TEFs are at risk of entrapment in atypical locations. Two of our follow-up cases of TEF presented with lodged peanuts. Such children are high-risk for FB lodgment and parents should be explained about the problems. We have also observed children with stomas with stenosis having lodged foreign bodies. Although most objects pass easily through the intestine, entrapment can occur at the pylorus, at the ligament of

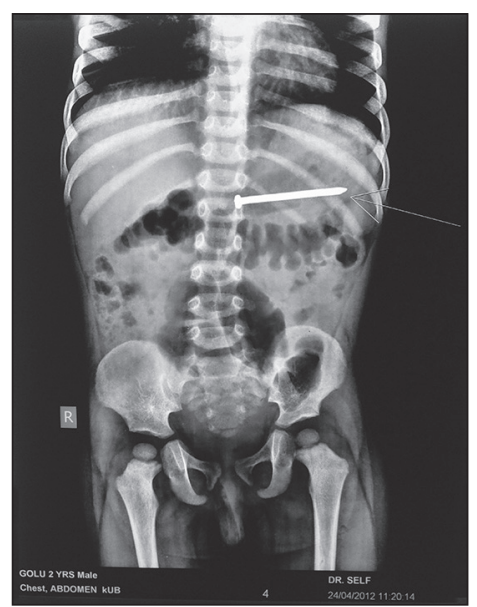

Figure 3: A sharp foreign body (nail) in stomach

\begin{tabular}{lcc}
\multicolumn{3}{l}{ Table 3: Complications } \\
Complications & Number & Percentages \\
\hline Septicemia & 6 & 7.3 \\
Wound infection & 4 & 4.8 \\
Esophageal stricture & 1 & 1.2 \\
Esophageal perforation & 1 & 1.2 \\
\hline
\end{tabular}

treitz, and at the ileocecal valve. ${ }^{[13]}$ The most common foreign bodies found in our study were coins. Objects' characteristics such as shape, dimension, and consistency are important in order to determine the damage that might occur. Stool et al. ${ }^{[14]}$ performed a retrospective study, in which they examined the characteristics of objects that had caused serious aerodigestive tract (airway, cricopharyngeal, or esophageal) injuries; with the definition of serious being indicated by the need of operative removal or the occurrence of death due to choking, as reported from the Consumer Product Safety Commission. Their results confirmed previous reports found in the medical literature, showing that the risk of injury or death posed by food, toy or toy part, or another object depends upon its size, shape, and consistency. ${ }^{[15,16]}$ In our series, we have observed three cases with complications. Two cases of acquired TEF were due to disc batteries, and one case of perforation peritonitis was due to sharp nail. Disc batteries were recognized with by presence of rim sign on X-ray. In battery ingestion, the mechanism of injury occurs by four different means including direct corrosive action due to leakage, toxic effect due to absorption of substances, low voltage burns, and pressure necrosis. ${ }^{[17-21]}$ Liquefaction necrosis and perforation can occur in 4-6 h after a disc battery is lodged in the esophagus and so removal is desirable within 6 h. ${ }^{[22-24]}$ For all the gastrointestinal foreign bodies, the type of object, its location, and child's symptoms dictate the treatment. In most cases of spontaneous passages occurs within $16 \mathrm{~h}$ of observation. ${ }^{[17]}$ Although most gastric objects pass without complications and can be observed in the outpatient setting, approximately $70 \%$ of esophageal objects remain entrapped, especially those in the upper or mid-esophagus. ${ }^{[18]}$ Our experience shows that the late presentation is due to delayed referral and misdiagnosis in peripheral centers. Late presentation is more common in asymptomatic cases. X-ray evaluation is indicated for all patients in whom an esophageal FB is suspected. ${ }^{[25]}$ However, a negative radiographic result does not exclude the presence of foreign bodies in the aerodigestive tract as radio-lucent objects such as rubber materials, groundnuts, and bolus of meat are not easily detected by plain radiography. Barium studies are also useful. ${ }^{[26]}$ In undetected cases, computed tomography (CT) scanning should be done. ${ }^{[27]}$ Endoscopic removal of foreign bodies in the aerodigestive tract using rigid scopes under general anesthesia has been reported to be a golden standard procedure. ${ }^{[25]}$ This is both a diagnostic and a management method and is generally recommended for most patients with a history of FB ingestion. Rigid endoscopy, as compared to flexible endoscopy is a useful method to diagnose and remove foreign bodies in the aerodigestive tract as it has a large lumen and allows better visualization of the potential anatomic sites of FB impaction in the aerodigestive tract. ${ }^{[28]}$ However, the procedure is not without risks, especial perforation, which has a high morbidity and potential mortality. Besides the surgical risks the patients are also subject to anesthetic risks. Other treatment modalities in the removal of foreign bodies in the aerodigestive tract include use of Magill forceps and Foley's catheter in the removal of foreign bodies in the esophagus. ${ }^{[2]}$ In this study, rigid endoscopy (esophagoscopy and bronchoscopy) with forceps removal under general anesthesia was the main treatment 
modality performed, which conforms with other studies. Magill forceps have also been found to be a possible method for removing coins from the upper esophagus or just below the cricopharynx. ${ }^{[30]}$ This method is minimally invasive and quick, and can be used in children with respiratory distress (because the airway is secure), or when the duration of coin impaction is indeterminate, or there has been previous esophageal surgery. ${ }^{[30]}$ In our study, the foreign bodies were successfully removed without complications in $90.8 \%$ of cases, which is similar to other studies reported elsewhere. ${ }^{[25]}$ The complications typically encountered include perforation, laceration, abscess formation, and mediastinitis. ${ }^{[31]}$ However, the complication and mortality rates in our study were found to be higher than that reported in other studies. ${ }^{[30]}$ The reasons for this observation could be as a result may be due to delayed referral and a failed, traumatic attempt in peripheral hospitals in hands of inexperienced operators. Surgery is rarely performed, but is relatively successful. ${ }^{[32,33]}$

\section{CONCLUSION}

Foreign bodies in the digestive tract of children are a common problem with diverse presentations. Disc battery ingestion is prone for complication and expedient removal is required. Associated conditions like repaired TEF or stoma with stenosis are high-risk factors for lodgment of foreign bodies.

\section{REFERENCES}

1. James, B, Snow JR. Bronchology. In: Colman, B.H., Ed., Disease of the Nose, Throat, Ear, Head and Neck, $14^{\text {th }}$ Edition, Churchill Livingstone 1991; p. 1278-96.

2. Rothmann BF, Boeckman CR. Foreign bodies in the larynx and tracheobronchial tree in children. A review of 225 cases. Ann Otol Rhinol Laryngol 1980;89:434-6.

3. Hamilton JK, Polter DE. Gastrointestinal foreign bodies. In gastrointestinal disease: Pathophysiology, Diagnosis and Management, editors. Sleisenger MH, Fordtran JS. W.B. Saunders Co: Philadelphia 1993; p. 286-92.

4. Yamamoto S, Suzuki K, Itaya T, Yamamoto E, Baba S. foreign bodies in the airway. Eighteen years retrospective study. Acta Otolaryngol (Suppl) 1996;525 6-8.

5. Khyani IA, Hirani I, Hussain SI, Mirza T, Alam J. Foreign bodies in aerodigestive tract. Experience at civil Hospital Karachi. Pak J Otolaryngol 2007;23:9-11.

6. Sehgal A, Singh V, Chandra J, Mathur NN. Foreign body aspirations. Indian Pediatr 2002;39:1006-10.

7. Rovin JD, Rodgers BM. Pediatric foreign body aspiration. Pediatr Rev 2000;21:86-90.

8. Schmidt $\mathrm{H}$, Manegold $\mathrm{BC}$. Foreign body aspiration in children. Surg Endosc 2000;14:644-8.

9. Akhtar M, Haq MI. Management of oesophageal foreign bodies. Prof Med J 2005;12:308-11.

10. Lin CH, Chen AC, Tsai JD, Wei SH, Hsueh KC, Lin WC. Endoscopic removal of foreign bodies in children. Kaohsiung J Med Sci 2007;23:447-52.

11. Cerri RW, Liacouras CA. Evaluation and management of foreign bodies in the upper gastrointestinal tract. Pediatr Case Rev 2003;3:150-6.

12. Macpherson RI, Hill JG, Othersen HB, Tagge EP, Smith CD. Esophageal foreign bodies in children: Diagnosis, treatment, and complications. AJR Am J Roentgenol 1996;166:919-24.

13. Louie MC, Bradin S. Foreign body ingestion and aspiration. Pediatr Rev 2009;30:295-301.

14. Stool D, Rider G, Welling JR. Human factors project: Development of computer models of anatomy as an aid to risk management. Int J Pediatr Otorhinolaryngol 1998;43:217-27.

15. Kenna MA, Bluestone CD. Foreign bodies in the air and food passages. Pediatr Rev 1988;10:25-31.

16. Wolach B, Raz A, Weinberg J, Mikulski Y, Ben Ari J, Sadan N. Aspirated foreign bodies in the respiratory tract of children: Eleven years experience with 127 patients. Int J Pediatr Otorhinolaryngol 1994;30:1-10.

17. Waltzman ML, Baskin M, Wypij D, Mooney D, Jones D, Fleisher G. A randomized clinical trial of the management of esophageal coins in children. Pediatrics 2005;116:614-9.

18 Tibbling L, Stenquist M. Foreign bodies in the esophagus. A study of causative factors. Dysphagia 1991;6:224-7.

19. Temple DM, McNeese MC. Hazards of battery ingestion. Pediatrics 1983;71:100-3.

20. Samad L, Ali M, Ramzi H. Button battery ingestion: Hazards of esophageal impaction. J Pediatr Surg 1999;34:1527-31.

21. Bass DH, Millar AJ. Mercury absorption following button battery ingestion. J Pediatr Surg 1992;27:1541-2.

22. Litovitz T, Butterfield AB, Holloway RR, Marion LI. Button battery ingestion: Assessment of therapeutic modalities and battery discharge state. J Pediatr 1984;105:868-73.

23. Shabino CL, Feinberg AN. Esophageal perforation secondary to alkaline battery ingestion. JACEP 1979;8:360-3.

24. Maves MD, Carithers JS, Birck HG. Esophageal burns secondary to disc battery ingestion. Ann Otol Rhinol Laryngol 1984;93:364-9.

25. Wai Pak M, Chung Lee W, Kwok Fung $H$, van Hasselt CA. A prospective study of foreign-body ingestion in 311 children. Int J Pediatr Otorhinolaryngol 2001;58:37-45.

26. Derowe A, Ophir D. Negative findings of esophagoscopy for suspected foreign bodies. Am J Otolaryngol 1994;15:41-5.

27. Mosca S, Manes G, Martino R, Amitrano L, Bottino V, Bove A, et al. Endoscopic management of foreign bodies in the upper gastrointestinal tract: Report on a series of 414 adult patients. Endoscopy 2001;33:692-6.

28. Revadi G, Philip R, Gurdeep S. Removal of foreign-bodies under general anaesthesia. A review of rigid endoscopy for foreign-bodies of the hypopharynx and oesophagus. Med J Malaysia 2010;65:143-5.

29. Soomoro MA, Akhtar JE. Foley balloon extraction of esophageal coins in children: A safe and cost-effective method. J Coll Physicians Surg Pak 2002;12:667-9.

30. Janik JE, Janik JS. Magill forceps extraction of upper esophageal coins. J Pediatr Surg 2003;38:227-9.

31. Lam HC, Woo JK, van Hasselt CA. Management of ingested foreign bodies: A retrospective review of 5240 patients. J Laryngol Otol 2001;115:954-7.

32. Güitrón A, Adalid R, Huerta F, Macías M, Sánchez-Navarrete M, Nares J. Extraction of foreign bodies in the esophagus. Experience in 215 cases. Rev Gastroenterol Mex 1996;61:19-26.

33. Athanassiadi K, Gerazounis M, Metaxas E, Kalantzi N. Management of esophageal foreign bodies: A retrospective review of 400 cases. Eur J Cardiothorac Surg 2002;21:653-6.

How to cite this article: Singh RB, Dubey RK, Pandey V, Kumar V, Sharma SP, Annavi B. Foreign bodies in digestive tract of children: A tertiary care hospital experience. Int J Med Public Health 2014;4:463-6.

Source of Support: Nil, Conflict of Interest: None declared. 